\title{
Dimethylamination and Formylation of Pyrimidines with Dimethylformamide ${ }^{1)}$
}

\author{
Sadao Nishigaki, Keitaro Senga, and Fumio Yoneda \\ Pharmaceutical Institute, School of Medicine, Keio University ${ }^{2)}$
}

(Received October 19, 1970)

\begin{abstract}
The convenient dimethylamination using dimethylformamide (DMF) of chloropyrimidines has been accomplished. Reaction of a chloropyrimidine and a 5-activated pyrimidine in DMF resulted in the simultaneous formation of a dimethylaminopyrimidine and a 5-formylpyrimidine which is further transformed in some cases.
\end{abstract}

The reaction of disubstituted formamide such as dimethylformamide with phosphorus oxychloride which displays the formylation of aromatic, ${ }^{3 a-e)}$ heterocyclic, ${ }^{4 a-e)}$ and activated olefinic compounds ${ }^{5)}$ is well known as Vilsmeier-Haack reaction. ${ }^{6)}$ The use of dimethylformamide (DMF) to replace the chlorine atoms in active chloro-compounds by dimethylaminogroups is also known. ${ }^{7 a-e)}$ Recently the extension of this application to some simple halogeno-pyridines and -quinolines to give the corresponding dimethylamino derivatives has been reported by Heindel and Kennewell. ${ }^{8)}$

As an independent observation, we have found that the dimethylamination can be extended to some chloropyrimidine; heating of 4-amino-6-chloro-2-methylpyrimidine (Ia) ${ }^{9}$ with phenol and anhydrous potassium carbonate in DMF give a mixture of expected 4-amino2-methyl-6-phenoxypyrimidine ${ }^{10)}$ and 4-amino-6-dimethylamino-2-methylpyrimidine (IIa). ${ }^{11}$ The failure to obtain exclusively 4-amino-2-methyl-6-phenoxypyrimidine prompted us to study the dimethylamination of chloropyrimidines with DMF. Thus treatment of Ia with excess DMF for several hours at $185^{\circ}$ resulted in the formation of the hydrochloride of IIa in satisfactory yield, which was converted to IIa by neutralization with aqueous ammonia. The reaction was extended successfully to 4-amino-2,6-dichloropyrimidine (Ib), ${ }^{12)}$ 4-amino-6-

1) A part of this work has been summarized in a recent communication: K. Senga, F. Yoneda, and S. Nishigaki, Chem. Pharm. Bull. (Tokyo), 19, 215 (1971).

2) Location: 35, Shinanomachi, Shinjuku-ku, Tokyo.

3) a) H.W. Moore and H.R. Snyder, J. Org. Chem., 29, 97 (1964); b) E. Campaigne and W.L. Archer, "Org. Synth.," Coll. Vol. 4. 1961 p. 331 ; c) W. Treibs, H.J. Neupert, and J. Hiebsch, Chem. Ber., 92, 141 $(1959)$; d) K. Hafner and K.H. Vöpel, Angew. Chem., 71, $672(1959)$; e) N.P. Buu-Höi and D. Lavit, J. Chem. Soc., 1955, 2776.

4) a) G.F. Smith, J. Chem. Soc., 1954, 3842; b) R.M. Silverstein, E.E. Rysliewcs, and C. Willard, “Org. Synth., Coll. Vol. 4. 1963, p. 831; c) E. Campaigne and W.L. Archer, J. Am. Soc., 75, 989 (1953); d) J. Clark and J.H. Lister, J. Chem. Soc., 1961, 5048; e) G. Cauguil and A. Casadevall, Compt. Rend., 240, 1784 (1955).

5) Z. Arnold and J. Zemlicka, Coll. Czechoslov. Chem. Commun., 24, 786, 2378, 2385 (1959) [ C. A., 54, 1274 (1960)].

6) A. Vilsmeier and A. Haack, Ber., 60B, 119 (1927).

7) a) G.M. Coppinger, J. Am. Chem. Soc., 76, $1372(1954)$; b) M. Wakabe and K. Hamano, Bull. Chem. Soc. Japan, 36, 230 (1963); c) D.S. Deorka and H.L. Sharma, J. Indian Chem. Soc., 40, 819 (1963); d) J.J. D'Amicom, S.T. Webster, R.H. Campbell, and C.E. Twine, J. Org. Chem., 30, 3618 (1965); e) L. Joseph and A.M. Albert, J. Heterocyclic Chem., 3, 107 (1966).

8) N.D. Heindel and P.D. Kennewell, Chem. Commun., 1969, 38.

9) Z. Fördi, G.V. Fodor, I. Demjen, H. Szeker, and I. Halmos, Chem. Ber., 75, 755 (1942).

10) S. Nishigaki, K. Ogiwara, K. Senga, K. Fukazawa, K. Aida, Y. Machida, and F. Yoneda, Chem. Pharm. Bull. (Tokyo), 18, 1385 (1970).

11) F. Craveri and G. Zoni, Bull. Sci. Fac. Chim. Ind. Bologna, 16, 126 (1958)[C. A., 53, 13161 (1959)].

12) S. Gabriel, Ber., 34, 3362 (1901). 
chloro-2-phenylpyrimidine (Ic), ${ }^{13)}$ 6-chloro-2,4-diaminopyrimidine (Id) ${ }^{\mathbf{1 4})}$ and 6,6'-dichloro-2, $2^{\prime}$-dimethyl-4,4'-iminodipyrimidine $(\mathrm{Ie})^{15)}$ to give 4 -amino-2,6-bis(dimethylamino)pyrimidine (IIb), ${ }^{16)}$ 4-amino-6-dimethylamino-2-phenylpyrimidine(IIc), ${ }^{17)}$ 2,4-diamino-6-dimethylaminopyrimidine (IId) and 6,6'-bis(dimethylamino)-2,2'-dimethyl-4,4'-iminodipyrimidine (IIe), ${ }^{15}{ }^{\prime}$ respectively.<smiles>[R]CN(N)N=C(Cl)C=[N+]=N</smiles>

Ia : $\mathrm{R}=\mathrm{CH}_{3}$

Ib : $\mathrm{R}=\mathrm{Cl}$

Ic : $\mathrm{R}=\mathrm{C}_{6} \mathrm{H}_{5}$

Id : $\mathrm{R}=\mathrm{NH}_{2}$

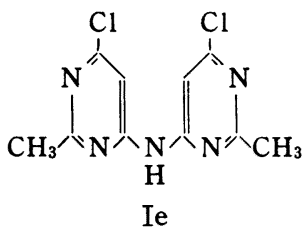
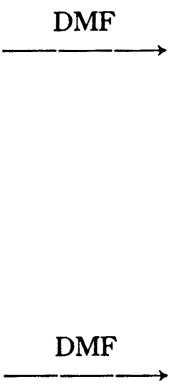

Chrat 1

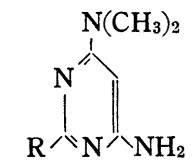

IIa : $\mathrm{R}=\mathrm{CH}_{3}$

IIb : $\mathrm{R}=\mathrm{N}\left(\mathrm{CH}_{3}\right)_{2}$

IIc : $\mathrm{R}=\mathrm{C}_{6} \mathrm{H}_{5}$

IId : $\mathrm{R}=\mathrm{NH}_{2}$

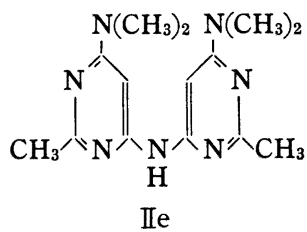

In the course of studies for the dimethylamination by DMF, we found the simultaneous utilization of formyl-group of DMF. Namely heating of Ia with equimolecular 6-amino-1, 3-dimethyluracil (If) ${ }^{18}$ in excess DMF at $185^{\circ}$ for 10 hours gave a mixture of the corresponding dimethylaminopyrimidine (IIa) and 1,3,7,9-tetramethyl-2,4,6,8-tetraoxo-1,2,3,4,6,7,8,9-octahydropyrido $[2,3-d, 6,5-d]$ dipyrimidine (IIf), ${ }^{19 a, b}$ in 93 and $53 \%$ yield respectively. Compound IIf was also prepared by heating of If and other chloropyrimidines such as $\mathrm{Ib}, \mathrm{Ie}, 4$ amino-5,6-dichloro-2-methylpyrimidine ${ }^{20}$ and 4 -amino-2,5,6-trichloropyrimidine ${ }^{21)}$ in DMF in similar yields. The product IIf was identical in all respects with authentic sample prepared by alternative routes. ${ }^{19 a, b)}$ The formation of IIf is apparently initiated by formylation of If followed by condensation of the resulting 6-amino-5-formyl-1,3-dimethyluracil with unchanged If. The use of 6-amino-1,3-diethyluracil $(\mathrm{Ig})^{18)}$ instead of If in this reaction afforded 1,3,7,9 - tetraethyl-2,4,6,8 - tetraoxo-1,2,3,4,6,7,8,9-octahydropyrido[2,3- $d, 6,5$ - $\left.d^{\prime}\right]$ dipyrimidine (IIg) in $45 \%$ yield. Similarly, the reaction of Ia and 4-amino-6-hydroxy-2-phenylpyrimidine (Ih) in DMF gave a mixture of IIa and 4,6-dioxo-2,8-diphenyl-3,4,6,7-tetrahydropyrido[2,3-d, 6,5- $\left.d^{\prime}\right]$ dipyrimidine (IIh). It should be mentioned here that when only If or Ig was heated under the same conditions, none of IIf or IIg was formed, starting materials being recovered.

When the reaction was applied to 4-amino-6-anilino-2-methylpyrimidine (Ii), ${ }^{22)}$ the reaction was stopped in the stage of 4-amino-6-anilino-5-formyl-2-methylpyrimidine (IIi).

13) E.C. Taylor and J. Weinstock, Brit. Patent 951655 (1964) [C. A., 61, 4387 (1964)].

14) G.B. Ellion and G.H. Hicthings, J. Am. Chem. Soc., 75, 4311 (1953).

15) S. Nishigaki, K. Senga, K. Ogiwara, and F. Yoneda, Chem. Pharm. Bull. (Tokyo), 18, 997 (1970).

16) Y. Nitta, K. Okui, and K. Ito, Chem. Pharm. Bull. (Tokyo), 13, 557 (1965).

17) J. Weinstock, U.S. Patent 2963478 (1960) [C. A., 55, 10482 (1961)].

18) J.H. Speer and A.L. Raymond, J. Am. Chem. Soc., 75, 114 (1953).

19) a) H. Bredereck, F. Effenberger, and R. Sauter, Chem. Ber., 95, 2049 (1962); b) R.C. Elderfield and M. Wharmby, J. Org. Chem., 32, 1638 (1967).

20) S. Nishigaki, K. Senga, and F. Yoneda, Chem. Pharm. Bull. (Tokyo), 18, 1925 (1970).

21) S.J. Childress and R.L. McKee, J. Am. Chem. Soc., 73, 3862 (1951).

22) A. Maggiolo, A.P. Phillips and G.H. Hitchings, J. Am. Chem. Soc., 73, 106 (1951). 
<smiles>[R]n1c(N)cc(=O)n([R])c1=O</smiles><smiles>[R]n1c(N)c(C=O)c(=O)n(C)c1=O</smiles><smiles></smiles>

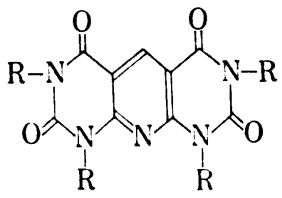<smiles>Cc1nc(N)cc(Cl)n1</smiles>

Ia<smiles>Cc1nc(N)cc(N(C)C)n1</smiles>

IIf : $\mathrm{R}=\mathrm{CH}_{3}$ IIg : $\mathrm{R}=\mathrm{C}_{2} \mathrm{H}_{5}$

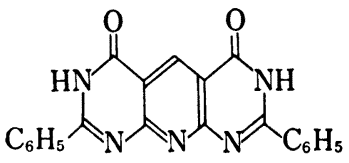

IIh<smiles>Cc1nc(N)c(C=O)c(Nc2ccccc2)n1</smiles>

$\mathrm{IIi}$

Chart 2

The structure assigned to IIi was based on elemental analysis, infrared (IR) spectrum mass spectrographic fragmentation and nuclear magnetic resonance (NMR) spectrum. The IR spectrum shows a carbonyl stretching absorption band at $1697 \mathrm{~cm}^{-1}$. The Mass spectrometry reveals a parent ion ( $m / e$ 228), M-28 and M-29 fragment ion which correspond to fragmentations of the formyl group. The absence of $\mathrm{C}-5$ proton and the presence of formyl proton in the NMR spectrum indicate that the formyl group was introduced to C-5 position of pyrimidine.

The reaction described above is the first examples of intermolecular simultaneous dimethylamination and formylation, which are applicable, in principle, to the reactions of other series as well as pyrimidine series. Although this reaction appears formally to be a new varient of Vilsmeier-Haack reaction, it can not be explained by the reaction mechanism described in books ${ }^{23}$ ) for Vilsmeier-Haack reaction. The mechanism is currently under investigation.

\section{Experimental ${ }^{24)}$}

4-Amino-6-dimethylamino-2-methylpyrimidine (IIa)__ A mixture of $0.43 \mathrm{~g}$ (0.003 mole) of 4-amino-6chloro-2-methylpyrimidine (Ia) and $5 \mathrm{ml}$ of DMF was heated for $5 \mathrm{hr}$ at $185^{\circ}$. After excess DMF was removed

23) For example, L.F. Fieser and M. Fieser, "Reagents for Organic Syntheses," John Wiley and Sons, Inc., New York, 1967, p. 284.

24) Melting points are uncorrected. IR spectra were determined on a Japan Spectroscopic Co., Ltd. spectrophotometer, Model IR-E, from samples mulled in Nujol. NMR spectra were taken at $60 \mathrm{Mc}$ with a Japan Electron Optics Lab. Co., Ltd. Model JNM-C-60-H spectrometer using tetramethylsilane as the internal references. 
under reduced pressure, the residue was dissolved in $2 \mathrm{~N} \mathrm{HCl}$, neutralized with $5 \%$ aq. $\mathrm{NH}_{3}$ and subjected to extraction with $\mathrm{CHCl}_{3}$. The $\mathrm{CHCl}_{3}$ solution was dried $\left(\mathrm{Na}_{2} \mathrm{SO}_{4}\right)$, and evaporated to dryness to give $0.3 \mathrm{~g}$ $(66 \%)$ of pale yellow crystals. Recrystallization from benzene gave colorless crystals, mp 189-191 . Anal. Calcd. for $\mathrm{C}_{7} \mathrm{H}_{12} \mathrm{~N}_{4}: \mathrm{C}, 55.24 ; \mathrm{H}, 7.95 ; \mathrm{N}, 36.82$. Found: $\mathrm{C}, 55.53 ; \mathrm{H}, 7.88 ; \mathrm{N}, 36.65$.

4-Amino-2,6-bis(dimethylamino)pyrimidine (IIb)_A mixture of $0.8 \mathrm{~g}$ (0.005 mole) of 4-amino-2,6dichloropyrimidine (Ib) and $10 \mathrm{ml}$ of $\mathrm{DMF}$ was heated for $7 \mathrm{hr}$ at $180^{\circ}$. After cooling the reaction mixture, separated needles were collected by filtration and dried to give pale yellow crystlas. The reaction product was dissolved in $2 \mathrm{~N} \mathrm{HCl}$, neutralized with $5 \%$ aq. $\mathrm{NH}_{3}$ and extracted with $\mathrm{CHCl}_{3}$. The extracts were dried $\left(\mathrm{Na}_{2} \mathrm{SO}_{4}\right)$ and evaporated to $0.4 \mathrm{~g}(44 \%)$ of pale yellow crystals. Recrystallization from $\mathrm{H}_{2} \mathrm{O}$ gave pale yellow needles, mp $114-116^{\circ}\left(\right.$ Lit. $^{16)} 116-117^{\circ}$ ). Anal. Calcd. for $\mathrm{C}_{8} \mathrm{H}_{15} \mathrm{~N}_{5}: \mathrm{C}, 53.01 ; \mathrm{H}, 8.34 ; \mathrm{N}$, 38.04. Found: C, 53.13; H, 8.37; N, 37.86.

4-Amino-6-dimethylamino-2-phenylpyrimidine (IIc)_-A mixture of $0.82 \mathrm{~g}$ (0.004 mole) of 4-amino-6chloro-2-phenylpyrimidine (Ic) and $5 \mathrm{ml}$ of $\mathrm{DMF}$ was refluxed for $3 \mathrm{hr}$ at $180^{\circ}$. After standing overnight at room temperature, the separated crystals were collected by filtration, washed with cold DMF and dried to give $0.7 \mathrm{~g}$ of faint yellow needles as hydrochloride of IIc. The hydrochloride was dissolved in a mixture of $2 \mathrm{~N} \mathrm{HCl}$ and $\mathrm{EtOH}$ with warming and neutralized with $5 \%$ aq. $\mathrm{NH}_{3}$. After cooling the solution, separated crystals were collected by filtration, washed with $\mathrm{H}_{2} \mathrm{O}$ and dried to give $0.55 \mathrm{~g}(64 \%)$ of colorless small needles. Recrystallization from EtOH and $\mathrm{H}_{2} \mathrm{O}$ gave colorless needles, mp 89-90.5 . Anal. Calcd. for $\mathrm{C}_{12} \mathrm{H}_{14} \mathrm{~N}_{4}$ : C, 67.26; H, 6.59; N, 26.15. Found: C, 67.49; H, 6.83; N, 25.44.

2,4-Diamino-6-dimethylaminopyrimidine (IId)—A mixture of $0.87 \mathrm{~g} \quad(0.006$ mole) of 6-chloro2,4-diamino (Id) and $5 \mathrm{ml}$ of DMF was refluxed for $5 \mathrm{hr}$ at $180-185^{\circ}$. After excess of DMF was removed under reduced pressure, the resulting yellow residue was dissolved in $10 \mathrm{ml}$ of $2 \mathrm{~N} \mathrm{HCl}$ with warming and made alkaline with $5 \%$ aq. $\mathrm{NH}_{3}$. The solution was subjected to extraction by $\mathrm{CHCl}_{3}$. The $\mathrm{CHCl}_{3}$ solution was dried $\left(\mathrm{Na}_{2} \mathrm{SO}_{4}\right)$ and evaporated to give $0.5 \mathrm{~g}(54 \%)$ of pale yellow powder. Recrystallization from benzene-EtOH gave colorless needles, mp 180-181 ${ }^{\circ}$. Anal. Calcd. for $\mathrm{C}_{6} \mathrm{H}_{11} \mathrm{~N}_{5}: \mathrm{C}, 47.04 ; \mathrm{H}, 7.24$; $\mathrm{N}, 45.72$. Found: $\mathrm{C}, \mathbf{4 6 . 8 1} ; \mathrm{H}, \mathbf{6 . 9 5} ; \mathrm{N}, \mathbf{4 5 . 4 2}$.

6,6'-Bis(dimethylamino)-2,2'-dimethyl-4,4'-iminodipyrimidine (IIe)-A mixture of $0.54 \mathrm{~g}$ (0.002 mole) of 6,6'-dichloro-2,2'-dimethyl-4,4'-iminodipyrimidine (Ie) and $10 \mathrm{ml}$ of DMF was refluxed for $6 \mathrm{hr}$ at $185^{\circ}$. The reaction mixture was allowed to stand at room temperature to precipitate the crystals, which were collected by filtration and washed with cold DMF to give $0.6 \mathrm{~g}$ of pale yellow crystals as hydrochloride of IId. The hydrochloride was dissolved in $10 \mathrm{ml}$ of $2 \mathrm{~N} \mathrm{HCl}$, and neutralized with $5 \%$ aq. $\mathrm{NH}_{3}$. After standing overnight at room temperature, separated crystals were collected by filtration, washed with $\mathrm{H}_{2} \mathrm{O}$ and dried to give $0.42 \mathrm{~g}(77 \%)$ of colorless crystals. Recrystallization from acetonitrile gave colorless needles, $\mathrm{mp}$ $160-162^{\circ}$. Anal. Calcd. for $\mathrm{C}_{14} \mathrm{H}_{21} \mathrm{~N}_{7}: \mathrm{C}, 58.51 ; \mathrm{H}, 7.37 ; \mathrm{N}, 34.12$. Found: $\mathrm{C}, 58.29 ; \mathrm{H}, 7.44 ; \mathrm{N}, 34.20$.

1,3,7,9-Tetramethyl-2,4,6,8-tetraoxo-1,2,3,4,6,7,8,9-octahydropyrido[2,3- $d, 6,5-d$ '] dipyrimidine (IIf)A mixture of $0.72 \mathrm{~g}(0.005$ mole) of Ia and $0.78 \mathrm{~g}(0.005 \mathrm{~mole})$ of 6 -amino-1,3-dimethyluracil (If) in $5 \mathrm{ml}$ of DMF was heated under refluxing for $10 \mathrm{hr}$. After cooling at room temperature, separated crystals were collected by filtration, washed with cold DMF and dried to give $0.4 \mathrm{~g} \mathrm{(53 \% )}$ of pale yellow crystals of IIf. Recrystallization from AcOH gave colorless needles, mp $320^{\circ}$, (Lit. ${ }^{19 a, b}$ ) mp $319-320^{\circ}, 315-316^{\circ}$ ). Anal. Calcd. for $\mathrm{C}_{13} \mathrm{H}_{13} \mathrm{O}_{4} \mathrm{~N}_{5}$ : C, 51.48; $\mathrm{H}, 4.32 ; \mathrm{N}, 23.09$. Found: $\mathrm{C}, 51.54 ; \mathrm{H}, 4.13 ; \mathrm{N}, 22.88$.

The filtrate was evaporated under reduced pressure. The resulting residue was dissolved in $2 \mathrm{~N} \mathrm{HCl}$ and neutralized with $5 \%$ aq. $\mathrm{NH}_{3}$. The solution was extracted with $\mathrm{CHCl}_{3}$, the extracts were dried $\left(\mathrm{Na}_{2} \mathrm{SO}_{4}\right)$ and evaporated to dryness to give $0.71 \mathrm{~g}(93 \%)$ of pale yellow crystals of IIa.

1,3,7,9-Tetraethyl-2,4,6,8-tetraoxo-1,2,3,4,6,7,8,9-octahydropyrido[2,3-d, 6,5-d']dipyrimidine (IIg)-A mixture of $0.57 \mathrm{~g}(0.004 \mathrm{~mole})$ of Ia and $0.73 \mathrm{~g}(0.004 \mathrm{~mole})$ of 6 -amino-1,3-diethyluracil (Ig) was heated at $185-190^{\circ}$ for $10 \mathrm{hr}$. After cooling the reaction mixture at room temperature, separated crystals were collected by filtration and dried to give $0.3 \mathrm{~g} \mathrm{(45 \% )}$ of yellow needles of IIg. Recrystallization from DMF gave colorless needles, $\mathrm{mp} 194-196^{\circ}$. Anal. Calcd. for $\mathrm{C}_{17} \mathrm{H}_{21} \mathrm{O}_{4} \mathrm{~N}_{5}: \mathrm{C}, 56.81 ; \mathrm{H}, 5.89 ; \mathrm{N}, 19.49$. Found: $\mathrm{C}, 56.58 ; \mathrm{H}, 5.86 ; \mathrm{N}, 19.77$.

In similar fashin to the preparation of IIf described above, $0.5 \mathrm{~g}(82 \%)$ of IIa was obtained as yellow powder from the filtrate.

4,6-Dioxo-2,8-diphenyl-3,4,6,7-tetrahydropyrido[2,3-d, 6,5-d'] dipyrimidine (IIh) —-A mixture of $0.72 \mathrm{~g}$ ( 0.005 mole) of Ia and $0.94 \mathrm{~g}$ (0.005 mole) of 4-amino-6-hydroxy-2-phenylpyrimidine (Ih) in $5 \mathrm{ml}$ of $\mathrm{DMF}$ was heated at $200^{\circ}$ for $10 \mathrm{hr}$. After cooling the reaction mixture, precipitated crystals were collected by filtration and dried to give $0.28 \mathrm{~g}(30 \%)$ of brown powder of IIh. Recrystallization from dimethyl sulfoxide (DMSO) gave pale yellow crystlals, $\mathrm{mp}>360^{\circ}$. Anal. Calcd. for $\mathrm{C}_{21} \mathrm{H}_{13} \mathrm{O}_{2} \mathrm{~N}_{5}: \mathrm{C}, 68.66 ; \mathrm{H}, 3.57 ; \mathrm{N}, 19.07$. Found: $\mathrm{C}, 68.83 ; \mathrm{H}, 3.49 ; \mathrm{N}, \mathbf{1 9 . 2 5}$.

The NMR spectrum $\left(\mathrm{CF}_{3} \mathrm{COOH}\right)$ exhibited a ten-proton multiplet at $7.82-8.47 \mathrm{ppm}\left(2 \mathrm{C}_{6} \mathrm{H}_{5}\right)$ and a one proton singlet at $9.96 \mathrm{ppm}\left(\mathrm{C}^{5} \mathrm{H}\right)$.

From the filtrate $0.7 \mathrm{~g}(92 \%)$ of IIa was obtained as yellow powder.

4-Amino-6-anilino-5-formyl-2-methylpyrimidine (IIi)_-A mixture of $0.57 \mathrm{~g}$ (0.004 mole) of Ia and $0.8 \mathrm{~g}(0.004 \mathrm{~mole})$ of 4-amino-6-anilino-2-methylpyrimidine (Ii) in DMF was refluxed for $8 \mathrm{hr}$ at $180-185^{\circ}$. 
After excess of DMF was removed under reduced pressure, the resulting residue was dissolved in $10 \mathrm{ml}$ of $2 \mathrm{~N} \mathrm{HCl}$ with warming and made alkaline with $5 \%$ aq. $\mathrm{NH}_{3}$. After standing overnight at room temperature, separated crystals were collected by filtration, washed with $\mathrm{H}_{2} \mathrm{O}$ and dried. The resulting crystals were extracted with hot benzene. The benzene insoluble materials were collected to give $0.5 \mathrm{~g}(53 \%)$ of pale yellow crystals of IIi. Recrystallization from EtOH- $\mathrm{H}_{2} \mathrm{O}$ gave colorless crystals, mp 177-178 . Anal. Calcd. for $\mathrm{C}_{12} \mathrm{H}_{12} \mathrm{ON}_{4}: \mathrm{C}, 63.14 ; \mathrm{H}, 5.30 ; \mathrm{N}, 24.55$. Found: C, 63.30; H, 5.25; N, 24.72.

The NMR spectrum (DMSO- $\left.d_{6}\right)$ exhibited a three-proton singlet at $2.27 \mathrm{ppm}\left(\mathrm{CH}_{3}\right)$, a one proton singlet at $5.70 \mathrm{ppm}(\mathrm{NH})$ and $8.80 \mathrm{ppm}(\mathrm{CHO})$, a two-proton singlet at $6.21 \mathrm{ppm}\left(\mathrm{NH}_{2}\right)$ and a five-proton multiplet at $6.94-7.62 \mathrm{ppm}\left(\mathrm{C}_{6} \mathrm{H}_{5}\right)$.

In similar fashion to the preparation of IIa, $0.55 \mathrm{~g}(90 \%)$ of IIa was obtained as yellow powder from the filtrate. 